\title{
Trichoderma harzianum as a tool for reaching suitable growth and vegetation cover on mine tailings
}

\author{
T.C. Regnier Department of Chemistry, Tshwane University of Technology, South Africa \\ N.S. Mokgalaka Department of Chemistry, Tshwane University of Technology, South Africa \\ O. Memel Department of Chemistry, Tshwane University of Technology, South Africa
}

M.D. Laing Department of Plant Pathology, African Centre for Crop Improvement, University of KwazuluNatal, South Africa

\begin{abstract}
Rapid and efficient revegetation of mining landscapes is always a challenge. One of the main difficulties in revegetation is the amount of plants species which are able to establish and survive in the harsh conditions often associated with mining. Finding a suitable growth medium is the initial requirement for the plant to produce an appropriate vegetation cover. Fast growing plants with a good root system are of interest as they not only immobilise metals but also prevent erosion and soil compaction. For this reason, it is important for the phytoremediation biotechnologies to have a better understanding of the potential growth of different plant species.

Recent publications have shown the potential interest of using grasses as the first stage of revegetation. The candidates should be fast growing and resist metal toxicity when planted on mine tailings. Many products have been registered as growth promoters. One of them, Eco-T, a fungal species (Trichoderma harzianum Rifai strain $\mathrm{kd}$ ) is currently produced in South Africa and well accepted as a growth promoter. AgriSil K50 a silica based product is known to provide a regular supply of potassium to the plant.

The Department of Chemistry at Tshwane University of Technology has been assessing the efficacy of this growth promoter Trichoderma harzianum (Eco-T) in increasing the growth of some grasses while buffering the soil contaminated by copper and arsenic. Anthericum saundersiae was used as a model plant to confirm the effect of Eco-T on growth under stress conditions, thus providing preliminary data for further application. This study was extended to Sorghum (Sorghum bicolor (L) Moench) to evaluate its use as a phytoremediation candidate and as an alternative source of income from biofuel production.

Initial results indicate that the combination of Eco-T and AgriSil K50 leads to a significant increase of the biomass, chlorophyll content in the presence of metals. This confirms that the application of this growth promoter in association with a chelating agent was able to reduce the toxic effect of the metals on the plants providing adequate stimulation of the root system and above ground biomass. In conclusion, this study highlights the importance of including growth promoters in the revegetation strategies.
\end{abstract}

\section{Introduction}

Various processes, including chemical, physical and biological techniques such as soil amendment, soil replacement, solidification, washing strategies and phytoremediation, are currently used to rehabilitate mine sites (Barceló and Poschenrieder, 2003; Tordoff et al., 2000). Phytoremediation, an eco-friendly alternative is gaining momentum worldwide. A wide variety of plants species may be used to accumulate metals, while stabilising the soil (Conesa et al., 2007; Whiting et al., 2004).

High biomass producing plants have been used in phytoremediation studies (Mleczek et al., 2010; Abhilash and Yunus, 2011). However, the root systems of many plants are located in the upper 5-20 cm layers of soil, while only a few can penetrate to deeper soil layers. Grasses, due to their unique morphological and physiological characteristics, are well known for their ability to control erosion and have been reported to be highly tolerant to metal contamination, salinity, drought and frost (Pang et al., 2003). Plant growth and resilience are some of the parameters considered during the selection of a suitable candidate for remediation. 
Contaminated soils are usually devoid of microflora and adding a growth promoter during the initial stages of the phytoremediation program could lead to a better performing plant cover.

Plant productivity is measured by the biomass produced through photosynthesis (Pidwirny, 2006). Potential candidates for phytoremediation must therefore comply with this basic criterion. Plant secondary metabolites significantly contribute to defensive measures against adverse biotic and abiotic stress (Petras et al., 2007). Biomarkers such as total soluble phenolic compounds can be used as indicators of tolerance or adaptation of the plant to metal induced stress (Rouxel et al., 1991; Mithöfer et al., 2004).

Trichoderma species are fungi that are common in soil and root ecosystems. Their symbiotic mode of action renders them beneficial for plant growth and development (Inbar et al., 1994). Recently, some studies have demonstrated the ability of Trichoderma to increase root-hair development, which contributes to better water use efficiency and uptake of macro- and micro-nutrients from the soil (Hoyos-Carvajal et al., 2009). Pioneering work by the University of KwaZulu Natal (South Africa) has proven that Eco-T, a Trichoderma harzianum strain-based product has potential as a plant growth promoter (Joubert, 2009).

Application of fertilisers as part of the phytoremediation strategy is a cost intensive option that is often regarded as a limitation (Petrisor et al., 2004). In addition, soil runoff may introduce nutrient-rich fertilisers into water streams causing eutrophication (Smith et al., 1999; Kahiluoto et al., 2011). AgriSil K50®, a commercially available product, can be used as a slow release agent for potassium, a vital nutrient for initial plant development.

The aim of this study was to assess the efficacy of Trichoderma harzianum (Eco-T) as a growth promoter of Anthericum saundersiae (Lily grass) growing on soils contaminated with copper and arsenic. The combination of Eco-T and AgriSil K50 was evaluated for its potential buffering capacity against metals. This study was extended to sorghum (Sorghum bicolor (L) Moench), to evaluate its use as a phytoremediation candidate and as an alternative source of income from biofuel production.

\section{$2 \quad$ Material and methods}

\subsection{Experimental design and growth conditions}

The initial experiment, with arsenic $\left(\mathrm{Na}_{2} \mathrm{HAsO}_{4} .7 \mathrm{H}_{2} \mathrm{O}\right)$ as metal contaminant $(100 \mu \mathrm{g} / \mathrm{L})$, was done using Anthericum saundersiae. Seedlings (10 cm height) obtained from a garden in Johannesburg were carefully rinsed with deionised water prior to planting. The seedlings (one seedling per cup) were planted in a $50 \mathrm{~mL}$ polystyrene cup containing $323 \mathrm{~g}$ of potting soil (Bark Unlimited, Varing Kwekery, Kameelfontein, South Africa) and left for seven days in a cool place with indirect sunlight. Daily watering (20 mL deionised water) was applied in order to allow establishment of the root system. All cups containing the seedlings were contaminated with $100 \mu \mathrm{g} / \mathrm{L}$ of arsenic $\left(\mathrm{Na}_{2} \mathrm{HAsO}_{4}\right.$. $\left.7 \mathrm{H}_{2} \mathrm{O}\right)$. Ten cups were used as control and did not receive any other amendment while 10 cups were amended every second day with $2 \mathrm{~mL}$ of a solution of Eco-T (1 gram for $1 \mathrm{~L}$ of deionised water), or amended once a week with $2 \mathrm{~mL}$ of a solution of AgriSil K50 $(0.833 \mathrm{~mL}$ for $1 \mathrm{~L}$ of deionised water) or with a combination of Eco-T and AgriSil K50.

For the trial using sorghum (Sorghum bicolor L.), five hundred seeds were surface-sterilised with $70 \%$ ethanol for $15 \mathrm{~min}$ and rinsed with deionised water prior to germination. Two days after germination in the dark at $25^{\circ} \mathrm{C}$, the seedlings (two seedlings per bag) were planted in a $1 \mathrm{~L}$ black bag containing $500 \mathrm{~g}$ of potting soil (Bark Unlimited, Varing Kwekery, Kameelfontein, South Africa) and left under a shade for seven days. The seedlings were watered daily. A $200 \mathrm{~mL}$ solution of each metal, copper $\left(\mathrm{CuSO}_{4}\right)$ or arsenic $\left(\mathrm{Na}_{2} \mathrm{HAsO}_{4} .7 \mathrm{H}_{2} \mathrm{O}\right)$, at different concentrations $(1,10,50$ and $100 \mu \mathrm{g} / \mathrm{L})$ were added at the beginning (day 1) of the experiment. The young seedlings were then inoculated once a week using AgriSil K50 ( $0.833 \mathrm{~mL}$ for $1 \mathrm{~L}$ of deionised water) while Eco-T ( $1 \mathrm{~g}$ for $1 \mathrm{~L}$ of deionised water, $200 \mathrm{~mL}$ per bag), was added every second day throughout the all experiment. Control plants were only watered with no amendments to the soil. Three weeks after regular microbial inoculations, the plants were harvested and the roots separated from the leaves. Roots and leaves were gently washed separately under running tap water before being freeze dried and stored until further use. 


\subsection{Growth parameters and chemical analysis}

Plant height, number of leaves and the biomass (dry weight) of each part was recorded for each plant. The chlorophyll a and chlorophyll b were extracted with cold acetone as described by Hendry and Price (1993) and expressed as gram of the compound per gram of dried weight.

The soluble phenolic compounds and condensed tannins were extracted from $50 \mathrm{mg}$ portions of the individual samples. Total soluble phenolic compounds were extracted as described by Mokgalaka-Matlala et al. (2010) using methanol:acetone:water (7:7:1, v:v:v). Extract solutions were stored at $4^{\circ} \mathrm{C}$ and the concentration of phenolic metabolites in each leaf extract was determined using the Folin-Ciocalteau assay (Swain and Hillis, 1959) and modified as described by Du Plooy et al. (2009). The total phenolic content of the plant extract was expressed as milligram of tannic acid equivalents per gram of dry plant material.

The amount of condensed tannins was measured using the vanillin- $\mathrm{HCl}$ method of Price et al. (1978) and expressed as mg catechin equivalent per gram of dry weight. All the analyses were performed using four replicates. All solvents used were of analytical grade (Merck Chemical Company, Johannesburg, South Africa).

The chlorophyll was extracted using acetone and the absorbance of extracts was determined at 480, 645 and $663 \mathrm{~nm}$ using a UV-Vis spectrophotometer (Biochrom Libra S22, Biochrom LTD, Cambridge, UK).

\subsection{Statistical analysis}

Calculation of averages and standard deviation (SD) values were done using Microsoft ${ }^{\circledR}$ Excel 2007 software. Differences between the total phenolics contents were subjected to an analysis of variance (ANOVA) using the general linear model (GLM). One way ANOVA (Pearson SPSS, version 14.0) was used to discriminate between the means.

\section{Data}

The outcomes of this study are presented in this section. Plant productivity was measured using biomass, and chlorophyll content as parameters while stress indicators were measured using total soluble phenolics and tannins content.

\subsection{Plant productivity and biomass}

The plant productivity and stress were first evaluated using A. Saundersiae (results not shown). The plants showed no signs of growth retardation even at high metal concentrations. There was no significant difference between the chlorophyll content of the A. Saundersiae plants exposed to metals and the control.

The trial was extended to Sorghum and the same parameters were evaluated. The total dry biomass of sorghum was measured after four weeks of growth and the results are given in Figure 1. 


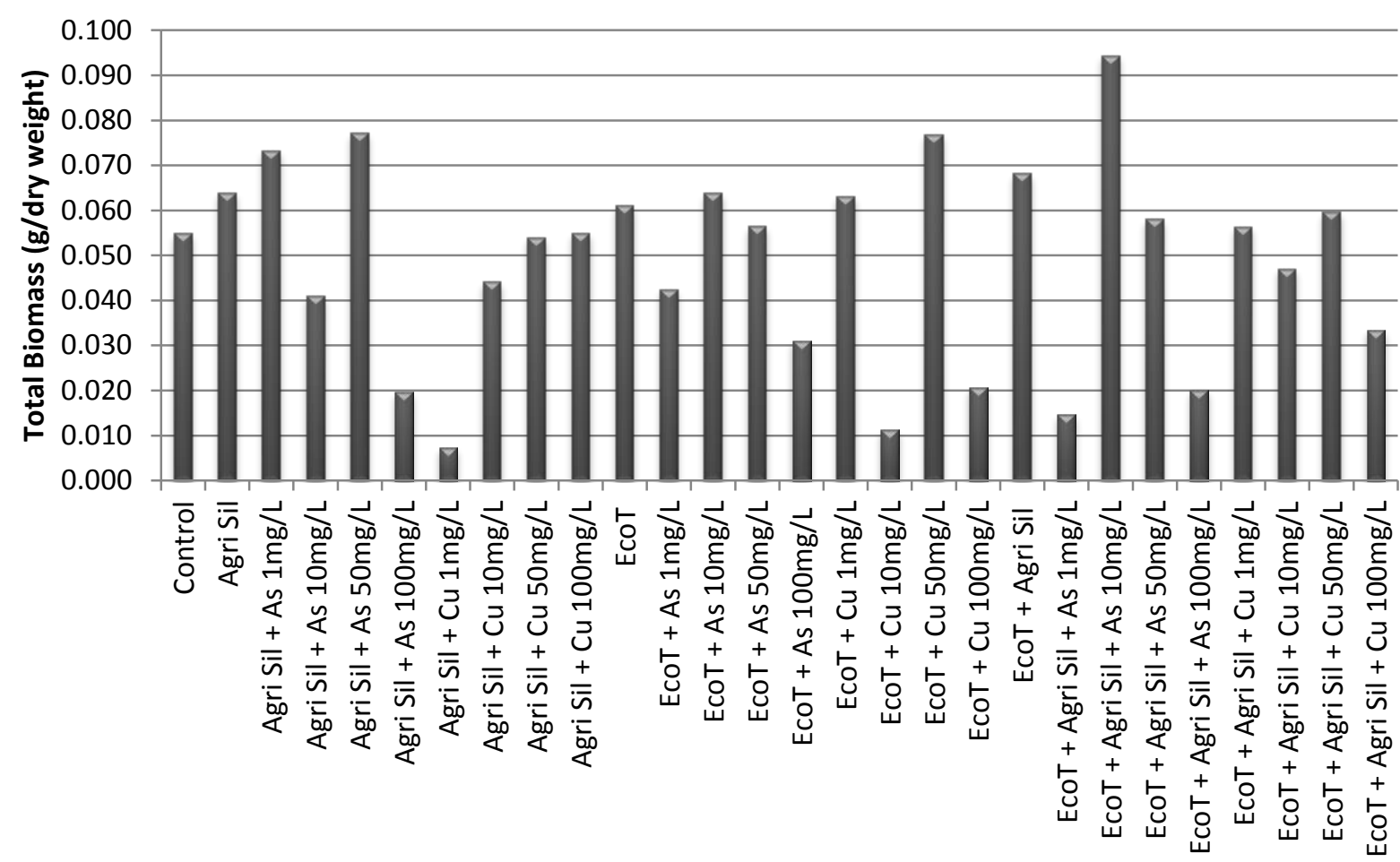

Figure 1 Total biomass produced by sorghum after 4 weeks of growth

Chlorophyll a, chlorophyll $\mathrm{b}$ were measured using dry plant material and total chlorophyll content of the sorghum leaves is given in Figure 2.

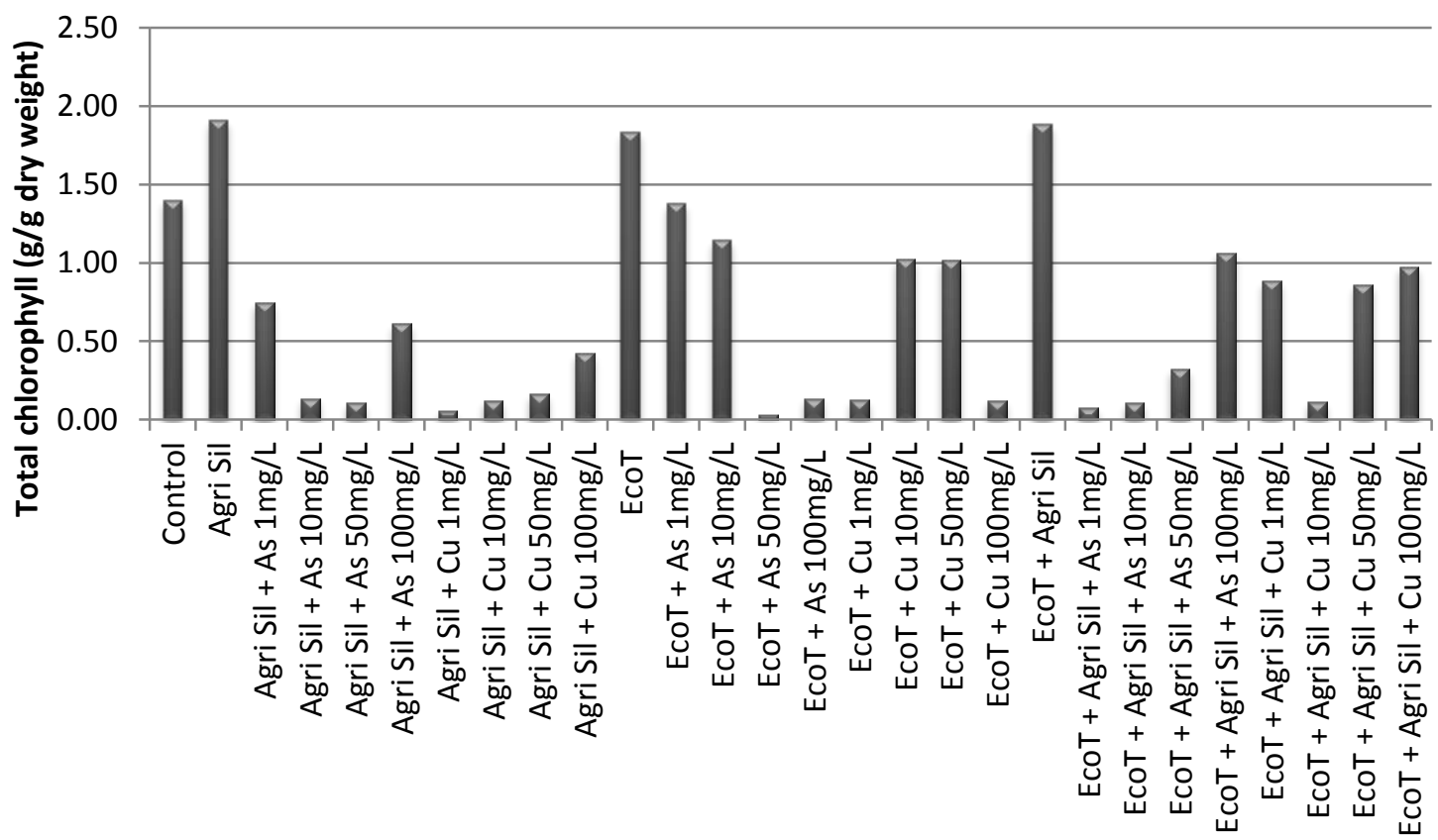

Figure 2 Total chlorophyll content of sorghum leaves after 4 weeks of growth 


\subsection{Total phenolics and tannins content}

Plant tolerance towards abiotic stress was evaluated by measuring the amount of phenolics produced by plants exposed to metals. The total phenolics content of leaves of A. Saundersiae (results not shown) exposed to metals was higher than those in the control.

The total phenolics and tannins content of sorghum plant extracts are given in Figures 3 and 4, respectively.

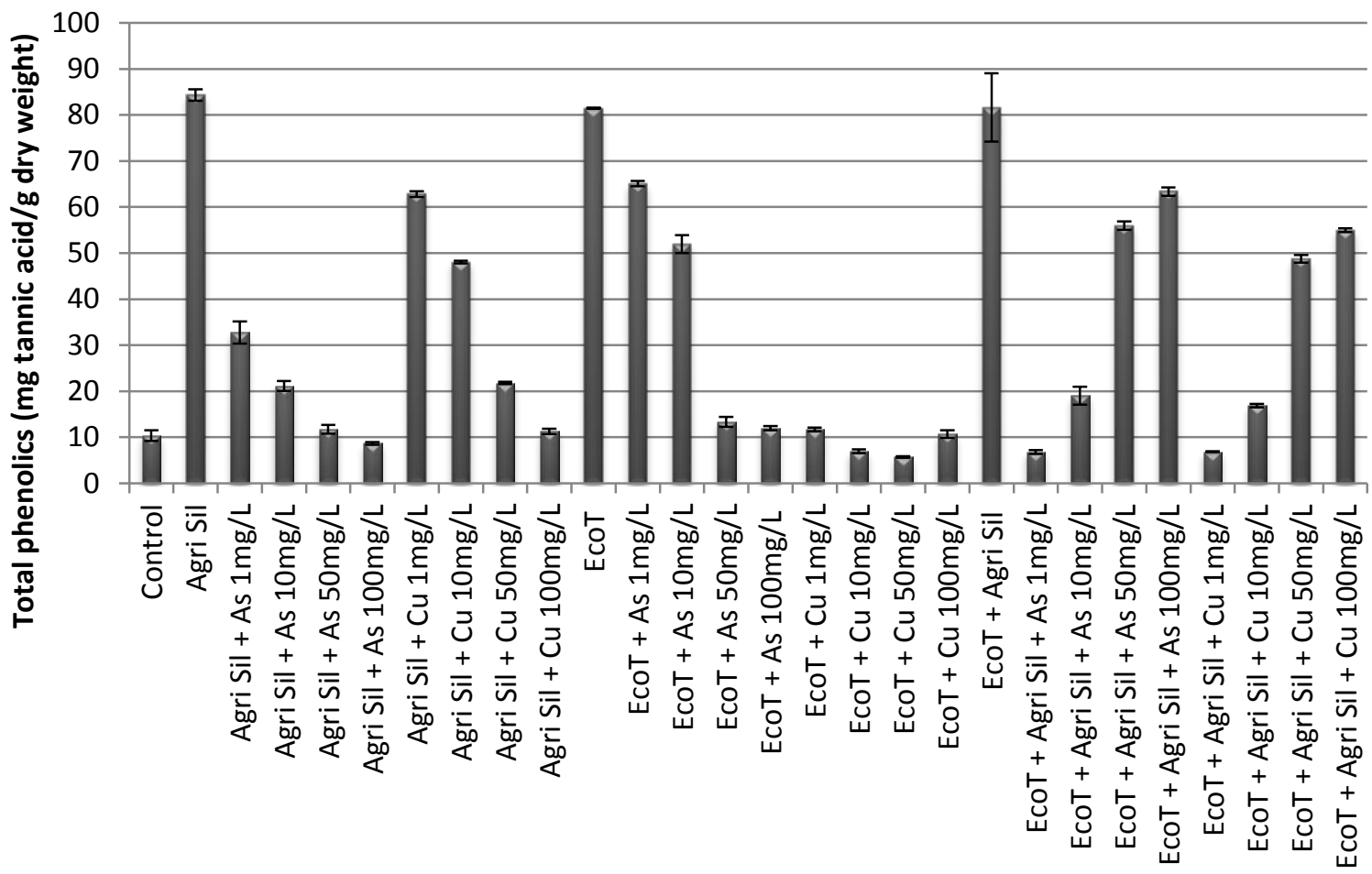

Figure 3 Total phenolics content obtained from methanolic extracts of sorghum leaves

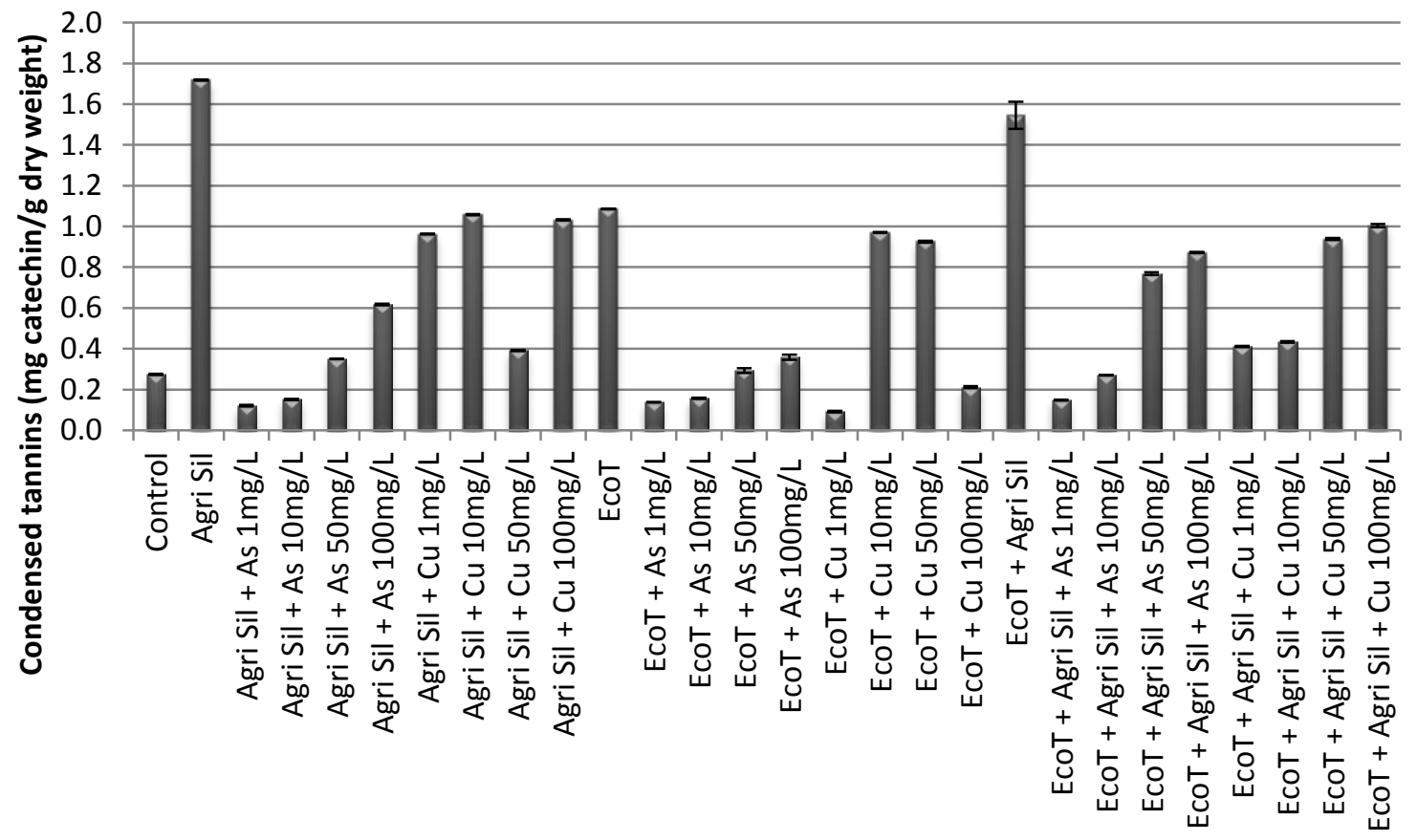

Figure 4 Condensed tannins content obtained from leaf extracts of sorghum 


\section{Discussion}

Pot trials are critical to guarantee the successful revegetation of contaminated substrata. Our initial approach was to select the most tolerant and resistant plant species through pot trials using artificial contamination and amendment of the soil. Thereafter, a pilot study in the actual contaminated area will allow evaluation of the ability of the plants to adapt to the prevailing conditions before full scale revegetation is undertaken.

In plants, exposure to toxic metals can influence various biochemical and physiological processes. Decreases in biomass and chlorophyll contents have been well documented. Such decreases are believed to be linked to passive water losses, major osmotic adjustment, iron depletion or substitution of magnesium and iron by toxic metals. In this study, the positive effects of Agrisil and Eco-T on the growth of sorghum were evident for all the plants subjected to As and $\mathrm{Cu}$ (Figure 1). This may be attributed to the ability of Agrisil and Eco-T to buffer abiotic stress through a symbiotic mode of action.

In the absence of metals, the chlorophyll content increased when Agrisil and Eco-T were added, either individually or in combination. All the plants exposed to $\mathrm{As}$ and $\mathrm{Cu}$ showed reduced chlorophyll content compared to the control. Generally, the addition of Agrisil and Eco-T was effective in maintaining adequate plant chlorophyll levels only at low metal concentrations (Figure 2). According to Vernay et al. (2007), increased metal concentrations reduce chlorophyll synthesis and the chlorophyllase activity due to metal induced toxicity.

Likewise, the highest levels of total phenolics were produced by plants treated with Agrisil and Eco-T, added either individually or together (Figure 3). In the presence of Agrisil, the amounts of phenolics produced increased with increasing As and $\mathrm{Cu}$ concentrations, except at $100 \mathrm{mg} / \mathrm{L}$ treatment. The plants exposed to Eco-T treatment produced significantly higher concentrations of phenolics in all As treatments compared to the control. On the contrary, $\mathrm{Cu}$ treatments seemed to lessen the production of phenolics in the presence of Eco-T. The combination of Agrisil and Eco-T significantly increased the phenolic contents of plants exposed to $\mathrm{As}$ and $\mathrm{Cu}$ at concentrations higher than $1 \mathrm{mg} / \mathrm{L}$, compared to the control. Exposure to high concentrations of toxic metals is known to induce the production of reactive oxygen species (ROS) by plants (Posmyk et al., 2008). It seems that the synthesis of phenolic metabolites is an effective strategy to mitigate cell damage resulting from the presence of such free radical species in sorghum.

Condensed tannins are known to have antioxidant and antigenotoxic activities (Posmyk et al., 2008). Metal toxicity may induce DNA damage and mutations resulting in reduced tolerance to stress. The addition of Agrisil significantly increased the tannin contents in sorghum compared to the control, Eco-T alone and Agrisil+Eco-T treatments. In the presence of $\mathrm{As}$ and $\mathrm{Cu}$, lower levels of tannins were produced, even when Agrisil and Eco-T were used to amend the soil. However, compared to the control, the plants exposed to As and $\mathrm{Cu}$ and amended with Agrisil and Eco-T, displayed significantly higher tannin contents. It would seem that metal concentrations higher than $10 \mathrm{mg} / \mathrm{L}$ induced the production of tannins when Agrisil and Eco-T were added to the soil.

\section{Conclusion}

The addition of AgriSil and Eco-T to soil was, in most cases, beneficial to the growth of sorghum plants exposed to $\mathrm{As}$ and $\mathrm{Cu}$. Adequate chlorophyll levels were maintained by plants, in spite of exposure to metals. This is an indication of healthy plant metabolism due to tolerance and adaptation to stress. Moreover, the addition of AgriSil and Eco-T facilitated the production of phenolic metabolites, known to be valuable towards protection from biotic and abiotic stress. Finally, amendment with AgriSil and Eco-T represents a promising approach for including growth promoters in revegetation strategies.

Sorghum is a valuable crop for production on areas contaminated by mining activities. However, the crop should only be utilised for biofuel production, since the potential of metal accumulation renders it unsuitable for consumption. In South Africa, food security is of concern, and therefore land owned by mining companies provides opportunities for growing biofuel crops without competing with food production on arable lands. 


\section{References}

Abhilash, P.G. and Yunus, M. (2011) Can we use biomass produced from phytoremediation? Biomass and Bioenergy, Vol. 35, pp. 1371-1372.

Barceló, J. and Poschenrieder, C. (2003) Phytoremediation: principles and perspectives, Contributions to Science, Vol. 2(3), pp. 333-344.

Conesa, H.M., Garcia, G., Faz, A. and Arnaldos, R. (2007) Dynamics of metal tolerant plant communities development in mine tailings from Cartagena-La Union Mining District (SE Spain) and their interest for further revegetation purposes, Chemosphere, Vol. 68, pp. 1180-1185.

Du Plooy, W., Regnier, T. and Combrinck, S. (2009) Essential oil amended coatings as alternatives to synthetic fungicides in citrus postharvest management, Postharvest Biology and Technology, Vol. 53, pp. 117-122.

Hendry, G.A.F. and Price, A.H. (1993) In Methods in Comparative Plant Ecology: A Laboratory Manual, G.A.F. Hendry and J.P. Grime (eds) Chapman and Hall, London, UK, pp. 148-151.

Hoyos-Carvajal, L., Orduz, S. and Bissett, J. (2009) Growth stimulation in bean (Phaseolus vulgaris L.) by Trichoderma, Biological Control, Vol. 51, pp. 409-416.

Inbar, J., Abramsky, M., Cohen, D. and Chet, I. (1994) Plant growth enhancement and disease control by Trichoderma harzianum in vegetable seedlings grown under commercial condition, European Journal of Plant Pathology, Vol. 100, pp. 337-346.

Joubert, R. (2009) Fungus that boosts potatoes, maize, Farmers Weekly, 22 May, p. 24.

Kahiluoto, H., Kuisma, M., Havukainen, J., Luoranen, M., Karttunen, P., Lehtonen, E. and Horttanainen, M. (2011) Potential of agrifood wastes in mitigation of climate change and eutrophication - two case regions, Biomass and Bioenergy, In press, doi:10.1016/j.biombioe.2011.01.058.

Mithöfer, A., Schulze, B. and Boland, W. (2004) Biotic and heavy metal stress response in plants: evidence for common signals, FEBS Letters, Vol. 566, pp. 1-5.

Mleczek, M., Rutkowski, P., Rissmann, I., Kaczmarek, Z., Golinski, P., Szentneer, K., Strażyńska, K. and Stachowiak, A. (2010) Biomass productivity and phytoremediation potential of Salix alba and Salix viminalis, Biomass and Bioenergy, Vol. 34, pp. 1410-1418.

Mokgalaka-Matlala, N.S., Combrinck, S., Regnier, T. and Weiersbye, I. (2010) Selection of tree species as assets for mine phytoremediation using the genus Rhus (Anacardiaceae) as a model, Proceedings Fifth International Conference on Mine Closure (Mine Closure 2010), A.B. Fourie, M. Tibbett and J. Wiertz (eds), 23-26 November 2010, Viña del Mar, Chile, Australian Centre for Geomechanics, Perth, pp. 343-350.

Pang, J., Chan, G.S.Y., Zhang, J., Liang, J. and Wong, M.H. (2003) Physiological aspects of vetiver grass for rehabilitation in abandoned metalliferous mine wastes, Chemosphere, Vol. 52, pp. 1559-1570.

Petras, M.S.C., Zheng, Q.A. and Sarma-Mamillapalle, V.K. (2007) The phytoalexins from Brassicaceae: structure, biological activity, synthesis and biosynthesis, Natural Product Communications, Vol. 2, pp. 319-330.

Petrisor, I.G., Dobrota, S., Komnitsas, K., Lazar, I., Kuperberg, J.M. and Serban, M. (2004) Artificial inoculation: perspectives in tailings phytostabilization, International Journal of Phytoremediation, Vol. 6(1), pp. 1-15.

Pidwirny, M. (2006) Primary productivityof plants, Fundamentals of Physical Geography, 2nd edition.

Posmyk, M.M., Kontek, R. and Janas, K.M. (2008) Antioxidant enzymes activity and phenolic compounds content in red cabbage seedlings exposed to copper stress, Ecotoxicology and Environmental Safety, Vol. 72, pp. 596-602.

Price, M.L., Van Scoyoc, S. and Butler, L.G. (1978) A critical evaluation of the vanillin reaction as an assay for tannin in sorghum grain, Journal of Agricultural Food Chemistry, Vol. 26(5), pp. 1214-1218.

Rouxel, T., Kollmann, A., Boulidard, L. and Mithen, R. (1991) Abiotic elicitation of indole phytoalexins and resistance to Leptosphaeria maculans within Brassiceae, Planta, Vol. 184, pp. 271-278.

Smith, V.H., Tilman, G.D. and Nekola, J.C. (1999) Eutrophication: impact of excess nutrient inputs on freshwater, marine, and terrestrial ecosystems, Environmental Pollution, Vol. 100, pp. 179-196.

Swain, T. and Hillis, W.E. (1959) The phenolic constituents of Prunus domestica I, The quantitative analysis of phenolic constituents, Journal of Science and Food Agriculture, Vol. 10, pp. 63-68.

Tordoff, G.M., Baker, A.J.M. and Willis, A.J. (2000) Current approaches to the revegetation and reclamation of metalliferous mine wastes, Chemosphere, Vol. 41, pp. 219-228.

Vernay, P., Gauthier-Moussard, C. and Hitmi, A. (2007) Interction of bioaccumulation of heavy metal chromium with water relation, mineral nutrition and photosynthesis in developed leaves of Lolium perenne L., Chemosphere, Vol. 68, pp. 1563-1575.

Whiting, S.N., Reeves, R.D., Richards, D., Johnson, M.S., Cooke, J.A., Malaisse, F., Paton, A., Smith, J.A.C., Angle, J.S., Chaney, R.L., Ginocchio, R., Jaffre, F.R., McIntyre, T., Purvis, O.W., Salt, D.E., Schat, H., Zhao, F.J. and Baker, A.J.M. (2004) Research priorities for conservation of metallophyte biodiversity and their potential for restoration and site remediation, Restoration Ecology Vol. 12, pp. 106-116. 
Trichoderma harzianum as a tool for reaching suitable growth and vegetation cover T.C. Regnier et al. on mine tailings 